\title{
Bran Fermentation with Lactobacillus Strains to Develop a Functional Ingredient for Sourdough Production
}

\author{
Zsolt Zalán ${ }^{1, ~}$, Ferenc Hegyi ${ }^{1}$, Erika Erzsébet Szabó ${ }^{1}$, Anita Maczó ${ }^{1}$, Erzsébet Baka ${ }^{2}$, Muying Du ${ }^{3}$, \\ Yuting Liao ${ }^{3}$, Kan Jianquan ${ }^{3}$ \\ ${ }^{1}$ Department of Biology, National Agricultural Research and Innovation Centre-Food Science Research Institute, Budapest, Hungary \\ ${ }^{2}$ Department of Environmental and Applied Microbiology, National Agricultural Research and Innovation Centre-Agro-Environmental \\ Research Institute, Budapest, Hungary \\ ${ }^{3}$ College of Food Science, Southwest University, Chongqing, P.R. China
}

Email address:

zs.zalan@cfri.hu (Z.Zalán)

\section{To cite this article:}

Zsolt Zalán, Ferenc Hegyi, Erika Erzsébet Szabó, Anita Maczó, Erzsébet Baka, Muying Du, Yuting Liao, Kan Jianquan. Bran Fermentation with Lactobacillus Strains to Develop a Functional Ingredient for Sourdough Production. International Journal of Nutrition and Food Sciences. Vol. 4, No. 4, 2015, pp. 409-419. doi: 10.11648/j.ijnfs.20150404.11

\begin{abstract}
The aim of the study was to select Lactobacillus strains according to their antifungal activity and fermentation properties for wheat and oat bran fermentation. The application of fermented brans as functional starter components for sourdough preparation was also examined as well as the applicability of fermented bran-enriched sourdough for bread making. We have compared also the effects of different components (bran, bran with lactobacilli and fermented bran) on the protein profiles of breads. Two Lactobacillus strains (Lb. delbrueckii subsp. bulgaricus 397 and Lb. curvatus 2768) with good antimicrobial and fermentation properties were selected to ferment wheat and oat bran to develop a fermented bran enriched sourdough. The fermented bran had not any significant influence on the commercial baker's yeasts and the prepared sourdough had positive effect on the properties of bread, among others on the protein profiles and the shelf-life of the sourdough bread. The results suggest that the lacto-fermentation is a potential bioprocessing technology to develop from bran a functional ingredient for sourdough production, which could be used after all for sourdough bakery products.
\end{abstract}

Keywords: Bran Fermentation, Lactobacillus, Sourdough

\section{Introduction}

The bran, the nutritious outer layer (aleurone and pericarp) of the cereal grain, is an important by-product of conventional milling process with little commercial value and produced worldwide in great quantities. In the grain the dietary fiber is concentrated in the outer layers, thus bran can contain $45-50 \%$ of fiber [1]. However the cereal bran is not only a significant source of dietary fiber but also rich in vitamins, minerals and phytochemicals $[2,3]$. Hence the cereal brans are important ingredients providing dietary fiber and they are the most common raw materials for increasing the level of dietary fiber in baking [4]. The extensive use of wheat bran as a food ingredient is limited, because it poses several technological problems, which are great challenges for the food industry. Native bran is not suitable to be directly used in food application, because bran has bitter taste, hard texture and high water-holding capacity [5, 2]. In baked products the bran supplementation decreases loaf volume or height and elasticity of the crumb, weakens the structure and baking quality of the dough, it causes textural modifications, changes in appearance and taste [2,6]. Moreover bran contains phytic acid which acts as an antinutrient due to its chelation of various metals and its binding of protein, therefore, diminishing the bioavailability of protein and nutritionally important minerals, however it has been reported, that phytic acid is also antioxidant and anticarcinogenic [7, 8]. By different bioprocessing techniques (involving fermentation) can be enhanced the biological value of bran and improved the bioaccessibility of the bioactive compounds [9]. The fermentation of bran has been shown to be an efficient pre-treatment method of bran on the one hand to improve sensory quality of bran-containing bread, and on the other hand to degrade antinutritive factors to improve mineral 
bioavailability $[3,6]$. One of the possible processes to improve the overall characteristics of bakery products is the use of sourdough. The sourdough is a mixture of flour and water that is fermented with lactic acid bacteria (LAB) and yeasts $[10,11$, 12]. The use of sourdough as natural starter for bread making is one of the oldest biotechnology processes in food production and it can be traced back to ancient times [10, 12]. Sourdough fermentation has shown several positive effects on the technological and nutritional functionality of bran among others reduces the phytic acid content $[2,13]$. Furthermore the sourdough fermentations enhance dough properties and improve volume, texture, flavor, and nutritional value of the bread and not least protect bread from mould and bacterial spoilage $[2,14,15,16]$. The sourdough fermentation is traditionally a spontaneous process, the microorganisms originate from flour, dough ingredients or the environment, but the microbial composition is especially influenced by the bakery environment $[11,17,18]$.

Microbiological studies have reported that more than 50 species of LAB and more than 20 species of yeasts occur in the ecological niche of sourdough, mostly species of the genus Lactobacillus, and genera Saccharomyces and Candida, but occasionally Leuconostoc spp., Weissella spp., Pediococcus spp., and Enterococcus spp. also have been found [10, 11, 12, 17]. Order to control the sourdough process and optimize the benefits of sourdoughs the application of defined starter cultures is necessary [15].

The bran fraction, and especially the pre-fermented bran, offers a great possibility to improve the sourdough fermentation and to develop a nutritious and healthy bran-enriched bakery product.

Therefore the aim of this study was to select LAB starter culture for bran fermentation and to investigate the applicability of this fermented bran in sourdough production and after all in bread making. For this purpose we have studied the antifungal activity, the fermentation properties of several lactobacilli on bran, the changes of microbial starters during sourdough production and the protein profile of bread prepared with fermented bran enriched sourdough.

\section{Materials and Methods}

\subsection{Microorganisms}

Twelve Lactobacillus strains, namely Lactobacillus (Lb.) plantarum 01, Lb. casei 2107, Lb. plantarum 2142, Lb. curvatus 2768, Lb. curvatus 2775, Lb. delbrueckii subsp. bulgaricus 397, Lb. fermentum D13, Lb. sakei DSM 20017, Lb. casei Shirota, Lb. rhamnosus VT1, Lb. rhamnosus GG, Lb. acidophilus N2 and one Lactococcus strain Lactococcus lactis subsp. lactis NCAIM B.02072 were investigated, grown in de Man, Rogosa and Sharpe (MRS) broth (Lab M Limited, Lancashire, United Kingdom). Four commercial instant dry baker's yeasts were used in this study from different origin, two from Hungarian market, Dr.Oetker yeast (Dr.Oetker Hungary Food Ltd.) and Budafoki yeast (Lesaffre Hungary) and two from Chinese market, Yestar (Angel Yeast Co., Ltd., China) and Angel (Angel Yeast Co., Ltd., China). The dry yeasts were used directly in the sourdough fermentation.

\subsection{Bran and Flour}

The used commercial oat and wheat bran originate from a Hungarian producer, Dénes-Natura Ltd., Pécs. Commercial white wheat flour (SPAR Hungary Trade Ltd.) was used for the sourdough and sourdough bread production containing 1 $\mathrm{g} / 100 \mathrm{~g}$ fat, $71 \mathrm{~g} / 100 \mathrm{~g}$ carbohydrates, $9,8 \mathrm{~g}$ protein/100 $\mathrm{g}$ and $3,2 \mathrm{~g} / 100 \mathrm{~g}$ dietary fiber.

\subsection{Bran Fermentation}

For fermentation $10 \mathrm{~g}$ bran and $90 \mathrm{ml}$ sterilized tap water were mixed in glass flask and inoculate with $1 \%$ Lactobacillus cell suspension. The cells from fresh, 24 hours culture in MRS were harvested by centrifugation at $6000 \mathrm{rpm}$ and $4{ }^{\circ} \mathrm{C}$ for 15 minutes and resolved in physiological saline solution $(0,85 \%)$ with peptone $(0,1 \%)$ before inoculation. The bran solution was incubated at $30{ }^{\circ} \mathrm{C}$ for 24 hours.

\subsection{Sourdough Preparation}

For sourdough production $160 \mathrm{~g}$ wheat flour and $96 \mathrm{~mL}$ fermented bran solution were mixed with $1,6 \mathrm{~g}(1 \% \mathrm{w} / \mathrm{w}$ on flour basis) dry yeast and they were mixed and kneaded by hand for $10 \mathrm{~min}$ until the correct consistency was obtained and then sourdough fermentation was carried out at $30^{\circ} \mathrm{C}$ for $16 \mathrm{~h}$.

\subsection{Bread Making}

The bread making was carried out according to Plessas et al. [17] with slight modification, briefly the base recipe is $400 \mathrm{~g}$ flour, $200 \mathrm{~g}$ sourdough $(50 \% \mathrm{w} / \mathrm{w}$ on flour basis), $6 \mathrm{~g}$ salt $(1.5 \%$ w/w on flour basis) and $200 \mathrm{~mL}$ tap water were kneaded for 15 $\min$. The dough rising were carried out at $30{ }^{\circ} \mathrm{C}$ for 2 hours. The dough was baked in Hauser BM-821 breadmaker (Hauser Electronic Hungary Ltd.). The recipe of sourdough bread was chosen for the base and the amount of water, the dry yeast, the bran and the Lactobacillus cells in the other breads were calculated from the sourdough, according to its microbial, bran and water content. Bread types were prepared according to recipes as reported in Table 1 .

Table 1. Composition of control, supplemented and sourdough bread.

\begin{tabular}{lllll}
\hline & Bread type & & & \\
\cline { 2 - 4 } Ingredient & Control (A) & Supplemented with bran (B) & $\begin{array}{l}\text { Supplemented with bran and } \\
\text { Lactobacillus cells (C) }\end{array}$ & $\begin{array}{l}\text { Sourdough bread (with } \\
\text { fermented bran) (D) }\end{array}$ \\
\cline { 2 - 5 } & Mass (g) & & 533 & 400 \\
\hline White wheat flour & 541 & 533 & - & 200 \\
Sourdough & - & - & - & \\
\hline
\end{tabular}




\begin{tabular}{|c|c|c|c|c|}
\hline \multirow{3}{*}{ Ingredient } & \multicolumn{4}{|l|}{ Bread type } \\
\hline & Control (A) & Supplemented with bran (B) & $\begin{array}{l}\text { Supplemented with bran and } \\
\text { Lactobacillus cells (C) }\end{array}$ & $\begin{array}{l}\text { Sourdough bread (with } \\
\text { fermented bran) (D) }\end{array}$ \\
\hline & \multicolumn{4}{|l|}{ Mass (g) } \\
\hline Salt & 6 & 6 & 6 & 6 \\
\hline Bran & - & 8 & 8 & - \\
\hline Dry yeast & 3,39 & 3,39 & 3,39 & - \\
\hline Tap water & 259 & 259 & 228 & 200 \\
\hline Lactobacillus cell suspension & - & - & 31 & - \\
\hline
\end{tabular}

\subsection{Assays}

\subsubsection{Lab, Yeast and Mesophilic Aerobic Microbes Enumeration and Isolation, $\mathrm{pH}$ Detection}

One gram or one $\mathrm{mL}$ of sample (sourdough, bread or fermented bran, respectively) was diluted in $9 \mathrm{~mL}$ of sterile physiological saline solution with peptone (peptone $1 \mathrm{~g} / \mathrm{L}$; $\mathrm{NaCl}$ 8,5 g/L) and homogenized (stock solution). Decimal dilutions were made in same dilution water. Lactobacilli were counted by pour plate method on MRS agar, the yeast were counted by surface-spread plate method on Potato Dextrose Agar (PDA) (Lab M Limited, Lancashire, United Kingdom) or Chloramphenicol Glucose Agar (CGA) (Scharlau Chemie S.A., Barcelona, Spain) and the mesophilic aerobic microbes were counted by surface-spread plate method on Nutrient agar (Scharlau Chemie S.A., Barcelona, Spain). Plates were incubated at $30{ }^{\circ} \mathrm{C}$ for $3-5$ days under aerobic conditions. For the isolation of LAB from the native flora of bran the fermented brans were used. After 24 hours natural fermentation of brans, from the appropriate dilution 20 microliters were spotted onto the surface of MRS plates and after incubation $\left(30{ }^{\circ} \mathrm{C}\right.$ for 3-5 days) separate colonies were picked up and transferred to MRS broth. The $\mathrm{pH}$ values of the fermented samples and bread were checked by a $\mathrm{pH}$-meter from the stock solutions (Mettler-Toledo $\mathrm{GmbH}$, Switzerland).

\subsubsection{Screening of Bacteria for Antifungal Activity}

The antifungal activity of the investigated lactobacilli was studied against six moulds (Aspergillus (Asp.) parasiticus, Asp. niger and four isolated moulds that grew on bread, from Aspergillus spp. and Penicillium spp.) and against the applied four baker's yeast. For the antifungal activity detection the double-layer agar spot method were used, when 10 microliters of the cell suspension of the Lactobacillus strains were spotted onto the surface of MRS agar and after one day incubation at $30{ }^{\circ} \mathrm{C}$ overlaid with soft Glucose-Peptone-Yeast extract agar contains yeast or mould spores in appropriate concentration.

\subsubsection{Determination of Dough Properties}

After the sourdough preparation 30 grams of dough was transferred into a $100 \mathrm{ml}$ glass beaker and the height and weight of doughs was measured before and after the fermentation to determine the factors that affect the quality of sourdough, the dough yield ((amount of flour + amount of water)*100/amount of flour), practical dough yield (weight of dough after the fermentation*100/weight of dough before the fermentation) and the maximal dough height.

\subsubsection{Identification of Bacterial Isolates}

Genomic DNA was extracted from pure cultures by using the UltraClean Microbial DNA Isolation kit (MoBio Laboratories, Inc., USA) according to the instructions of the manufacturer. These genomic DNA samples were used as templates for the amplification of target gene. 16S rDNA was amplified by PCR using bacterial 27f (5AGAGTTTGATCMTGGCTCAG-3) and 1492r (5-TACGG YTACCTTGTTACGACTT-3) primers [26]. The following thermal profile was used in a Eppendorf Mastercycler PCR machine (model number: 5333, Eppendorf, Hamburg, Germany): initial denaturation at $95^{\circ} \mathrm{C}$ for $5 \mathrm{~min}$, followed by 30 cycles consisting of denaturation at $94^{\circ} \mathrm{C}$ for $30 \mathrm{~s}$, annealing at $52^{\circ} \mathrm{C}$ for $30 \mathrm{~s}$, and elongation at $72^{\circ} \mathrm{C}$ for $1 \min 30$ $\mathrm{s}$, followed by a final extension at $72^{\circ} \mathrm{C}$ for $10 \mathrm{~min}$. The PCR reaction mixture contained $200 \mathrm{mM}$ of each deoxynucleoside triphosphate, $1 \mathrm{U}$ of DreamTaq DNA Polymerase (recombinant) (Thermo Fisher Scientific Inc., Waltham, MA USA), $1 \mathrm{X}$ Taq buffer with $\left(\mathrm{NH}_{4}\right)_{2} \mathrm{SO}_{4}$ (Thermo Fisher Scientific Inc., Waltham, MA USA), $2 \mathrm{mM} \mathrm{MgCl} 2,0.5 \mathrm{mM}$ of each primer, and about $30 \mathrm{ng}$ of genomic DNA template in a total volume of $50 \mu \mathrm{L}$. Direct sequencing of the obtained PCR products was performed by Baseclear Inc. (Leiden, The Netherlands). The sequences were edited to exclude the PCR primer binding sites and manually were corrected using MEGA 4 version software. The partial gene sequences of strains were compared automatically using the leBiBi and NCBI Blast databanks (https://umr5558-bibiserv.univ-lyon1.fr/lebibi/lebibi.cgi and http://www.ncbi.nlm.nih.gov) against the sequences of bacteria available in databanks.

\subsubsection{The Determination of Protein Profile by 2-DE}

For 2-DE (two-dimensional electrophoresis) analysis the bread samples were ground to a fine powder with Retsch Grindomix GM-200laboratory mill. For the first dimension the isoelectric focusing (IEF) was carried out in PROTEAN IEF Cell (Bio-Rad) using a commercial IPG (immobilized pH gradient) strips with $\mathrm{pH}$ range of 3-10 by linearly increasing voltage from $250 \mathrm{~V}$ to $24.000 \mathrm{Vh}$.

The strips were rehydrated in $250 \mu \mathrm{L}$ rehydration buffer $(8$ M urea, 1\% CHAPS [3-(3- Cholamidopropyldimethylammonio)-1-propanesulfonate hydrate], $20 \mathrm{mM}$ DTT [DL-threo-1,4-dimercapto-2,3-butanediol]) containing $200 \mu \mathrm{g}$ protein of the bread meal. Following the isoelectric focusing the strips were incubated in equilibrating buffer $(2 \%$ SDS, $6 \mathrm{M}$ urea, 1.5 M Tris- $\mathrm{HCl}$ (pH8.8), 20\% glycerol) containing 2\% 
DTT for $15 \mathrm{~min}$, and $2.5 \%$ iodoacetamide for $15 \mathrm{~min}$ at room temperature. For the second dimension, $15 \%$ SDS-PAGE was carried out with $1 \mathrm{~h}$ run at $200 \mathrm{~V}$ in Mini-PROTEAN II cell (BioRad). The gels were fixed in 20\% TCA (trichloracetic acid) and stained with Commassie Brilliant Blue R-250. The protein spots containing gels were evaluated by PDQUEST software, version 6.1 (Bio-Rad).

\section{Results and Discussion}

\subsection{Lactobacillus Strain Pre-Selection by their Antifungal Activity}

The antifungal activity of the potential starter culture is very important. On the one hand their anti-mould activity is
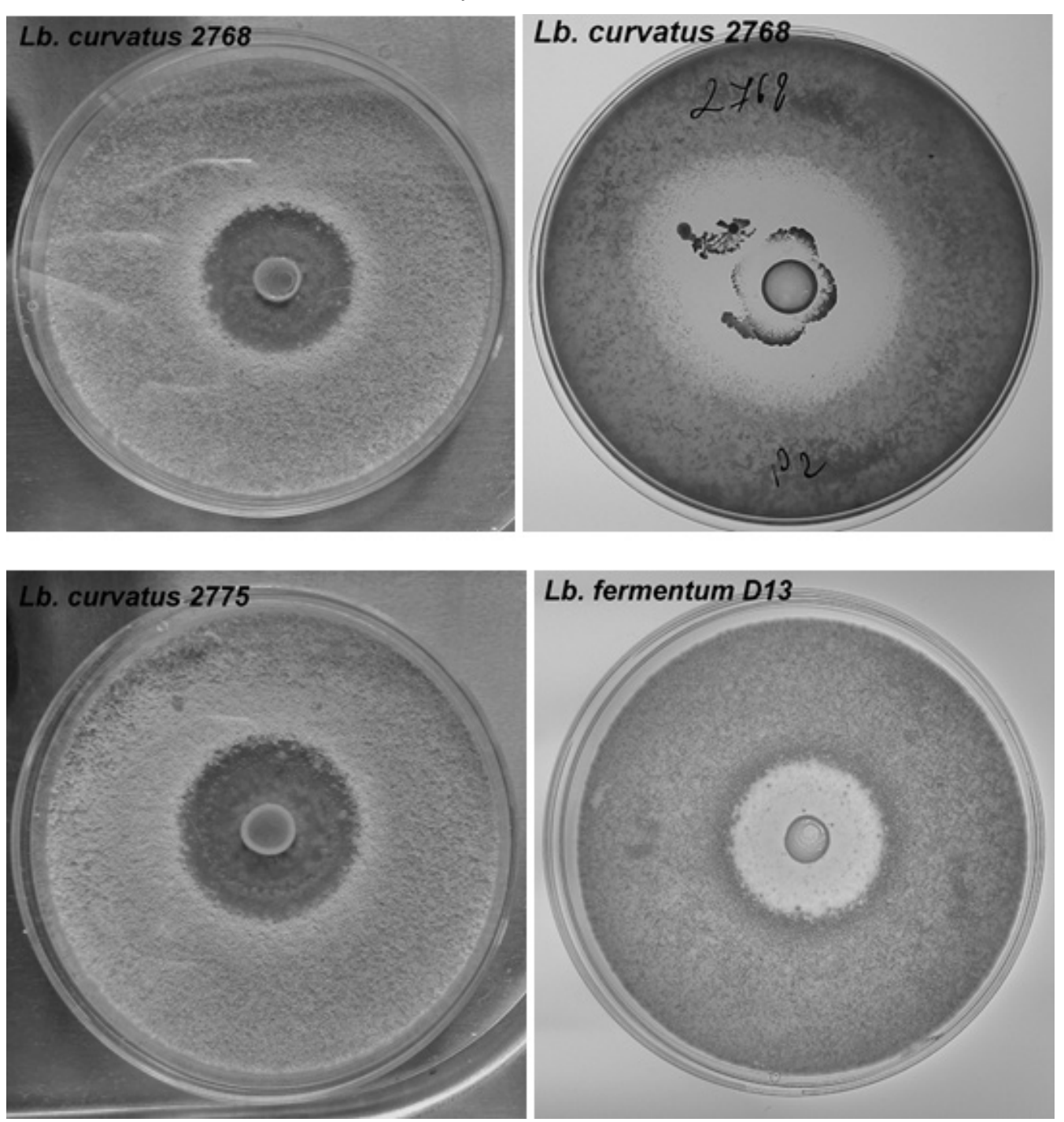

Fig. 1. Inhibition zones of growth of Penicillium sp. formed around colonies of Lactobacillus strains.

In this study four different baker's yeasts were chosen to investigate the effect of yeast on the sourdough production and on the other side the effect of fermented bran on the yeast activity. Since the number of Saccharomyces cerevisiae on the raw material is low and their occurrence in the spontaneously fermented sourdough could be explained by the application of essential, because the bread is very susceptible to attack by moulds and because of it has a short shelf-life and the bread spoilage by moulds cause a great economic losses, and on the other hand in the sourdough microbial community is of primary importance that the LAB strains do not inhibit the baker's yeast activity [19]. From the summarized inhibitory activity can be concluded, that nine Lactobacillus strains showed average or better than average antimould activity, the strains Lb. plantarum 01, Lb. casei 2107, Lb. plantarum 2142, Lb. curvatus 2768 , Lb. curvatus 2775 , Lb. delbrueckii subsp. bulgaricus 397, Lb. fermentum D13, Lb. sakei DSM 20017 and Lb. rhamnosus VT1. From these strains the Lb. curvatus 2768, Lb. curvatus 2775 and Lb. fermentum D13 showed especially great inhibitory activity against moulds (Fig. 1).

baker's yeast in bakery practice [20], in recent study for the reason of controlled rising the application of baker's yeast was indispensable. The investigated Lactobacillus strains have only weak inhibitory effect against baker's yeasts, however the results showed the yeasts originated from China are more sensitive to the LAB activity (Table 2.). 
Table 2. Inhibition of growth of baker's yeast by Lactobacillus strains.

\begin{tabular}{|c|c|c|c|c|}
\hline \multirow{2}{*}{$\begin{array}{l}\text { Lactobacillus } \\
\text { strains }\end{array}$} & \multicolumn{4}{|c|}{ Baker's yeast } \\
\hline & Yestar & Dr.Oetker & Angel & Budafoki \\
\hline 01 & - & - & + & \pm \\
\hline 2017 & \pm & \pm & - & \pm \\
\hline 2142 & + & + & + & \pm \\
\hline 2768 & \pm & - & - & - \\
\hline 2775 & + & - & \pm & - \\
\hline 397 & - & - & - & - \\
\hline D13 & + & + & + & - \\
\hline Sakei & ++ & - & - & - \\
\hline Shirota & - & + & + & - \\
\hline VT1 & - & - & - & - \\
\hline GG & + & \pm & \pm & \pm \\
\hline Lc. lactis & - & - & \pm & + \\
\hline N2 & - & - & + & - \\
\hline
\end{tabular}

The following scale was used: $(-)$ no inhibition, $( \pm)$ weak inhibition with small clear zone of inhibition around the bacterial colony or decreased yeast colony density, $(+)$ inhibition with good clear zone of inhibition around the bacterial colony, $(++)$ good inhibition with large clear zones around bacterial colonies

From the point of view of the development of an efficacious sourdough starter culture it is essential to avoid any negative interaction between the LAB and yeast. From the investigated Lactobacillus strains only two, the Lb. rhamnosus VT1 and Lb. delbrueckii subsp. bulgaricus 397 seemed to be the best for this reason, however the strain $\mathrm{Lb}$. curvatus 2768 also has only a weak inhibition against one yeast. Based on the summarized antifungal activity we have choosen the strains Lb. rhamnosus VT1, Lb. delbrueckii subsp. bulgaricus 397, Lb. curvatus 2768 and Lb. sakei DSM 20017 for the further investigations.

\subsection{Bacterial Isolates from Bran}

For starter culture the one of the best and logical choice is a strain from the autochthonous flora of the raw material. For this reason bacterial cultures were isolated from the wheat and oat bran and identified by DNA based methods. According to this investigation the isolated, dominant bacteria in the natural fermented wheat bran was the Weissella confusa and in the natural fermented oat bran was the Enterococcus faecium. The presence of these species are not strange in the fermented cereal product, since the member of the Weissella and Enterococcus genera, and namely these two species, are important members of the natural fermented sourdough microbiota and could be also predominant in spontaneously fermented bran [10-12, 14, 18, 27, 28]. However these genera, and mainly the Weissella, may play a role just during the first phase of the fermentation [12], and for this reason the application of the isolated strains is possible only beside Lactobacillus starter culture.

\subsection{Bran Fermentation}

The cell number of inoculated Lactobacillus strains, the mesophilic aerobic cell number and the $\mathrm{pH}$ were determined at the beginning, the 24. and 48. hours of fermentation. All of the selected Lactobacillus strains grew well both on the wheat and oat bran, they reached the $10^{9} \mathrm{cfu} / \mathrm{ml}$ cell concentration already by the 24 . hours of fermentation from the initial $10^{7}$ $\mathrm{cfu} / \mathrm{ml}$ cell number (Table 3 ).

Table 3. Growth of the starter culture and the changes of $\mathrm{pH}$ during the wheat (A) and oat (B) bran fermentation.

A)

\begin{tabular}{llllll}
\hline \multirow{2}{*}{ Lactobacillus strains } & \multicolumn{2}{l}{ Lactobacillus cell number $(\mathbf{c f u} / \mathbf{m l})$} & \multicolumn{2}{l}{ pH } \\
\cline { 2 - 6 } & Initial & $\mathbf{2 4}$ hours & $\mathbf{4 8}$ hours & Initial & $\mathbf{2 4}$ hours \\
\hline Lb. sakei & $6.25 * 10^{7}$ & $1.56 * 10^{9}$ & $1.18 * 10^{9}$ & 6.98 & 3.83 \\
397 & $2.41 * 10^{7}$ & $2.48 * 10^{9}$ & $1.73 * 10^{9}$ & 6.98 & 3.67 \\
2768 & $7.75 * 10^{7}$ & $1.13 * 10^{9}$ & $7.75 * 10^{8}$ & 6.98 & 3.5 \\
VT1 & $9.25 * 10^{7}$ & $1.15 * 10^{9}$ & $1.05 * 10^{9}$ & 6.98 & 3.96 \\
control & 0 & $4.1 * 10^{8}$ & $3.26 * 10^{8}$ & 7.1 & 3.78 \\
\hline
\end{tabular}

B)

\begin{tabular}{lllllll}
\hline \multirow{2}{*}{$\begin{array}{l}\text { Lactobacillus } \\
\text { strains }\end{array}$} & \multicolumn{2}{l}{ Lactobacillus cell number $(\mathbf{c f u} / \mathbf{m l})$} & $\mathbf{p H}$ & & \\
\cline { 2 - 7 } & Initial & $\mathbf{2 4}$ hours & $\mathbf{4 8}$ hours & Initial & $\mathbf{2 4}$ hours & $\mathbf{4 8}$ hours \\
\hline Lb. sakei & $6.25 * 10^{7}$ & $1.26^{*} 10^{9}$ & $1.17 * 10^{9}$ & 6.88 & 3.95 & 3.84 \\
397 & $2.41 * 10^{7}$ & $1.21 * 10^{9}$ & $1.4 * 10^{9}$ & 6.88 & 4.01 & 3.91 \\
2768 & $7.75 * 10^{7}$ & $5.58 * 10^{8}$ & $7.0^{*} 10^{8}$ & 6.88 & 4.1 & 4.12 \\
VT1 & $9.25 * 10^{7}$ & $1.12 * 10^{9}$ & $1.42 * 10^{9}$ & 6.88 & 4.33 & 4.25 \\
control & 0 & $4.5 * 10^{6}$ & $8 * 10^{6}$ & 6.9 & 4.93 & 4.64 \\
\hline
\end{tabular}

These results agree with other studies about bran fermentation, where the lactic acid bacteria have reached similar $10^{9} \mathrm{cfu} / \mathrm{ml}$ cell concentration [5]. In the spontaneous fermentation the lactic acid bacteria showed $10^{8}$ and $10^{6}$ $\mathrm{cfu} / \mathrm{ml}$ on wheat and oat bran, respectively, after the 24 . hour, which indicates that the application of starter culture to reach the appropriate living cell concentration is necessary. The total cell number counted on nutrient plate demonstrated the natural flora of brans have reached the $10^{6}-10^{7} \mathrm{cfu} / \mathrm{ml}$ after 24 hours incubation in the spontaneous fermentation, while beside the starter culture this number was lower, especially in case of the strains Lb. delbrueckii subsp. bulgaricus 397 and Lb. curvatus 2768, where the starter culture almost totally inhibited the autochthonous flora (Fig 2.). However by the 48 . hour the 
number of the indigenous flora has grown the inhibitory activity of starter cultures was even significant particularly in case of the Lb. curvatus 2768 strain. This antimicrobial activity was strain-dependent, but it was influenced also by the substrate and their natural microflora, which could be seen well in case of the strains Lb. sakei and Lb. delbrueckii subsp. bulgaricus 397 . The $\mathrm{pH}$ decrease was better in the wheat bran, where it drops under the $\mathrm{pH} 4$ within the first 24 hours, which is important from point of view of the microbial safety (Table 3). On the oat bran the acidification was slighter, especially by the strain Lb. rhamnosus VT1. The $\mathrm{pH}$ of the controls, the spontaneously fermented brans, was higher than the $\mathrm{pH}$ of samples with starter culture in every case. The $\mathrm{pH}$ decreasing was also significantly influenced by the substrate and the applied strains. The number of autochthonous microflora of bran is much higher than in flour [21]. Therefore, adding starter cultures to the bran instead of spontaneous fermentation is advisable, as our results also showed. According to their properties we have chosen the strains Lb. delbrueckii subsp. bulgaricus 397 and Lb. curvatus 2768 for the further investigations. It was observed that the cell concentration of starter cultures reached the maximal values already after the first 24 hours and the decreasing of $\mathrm{pH}$ was only moderate in the second 24 hours, which indicate that for the main fermentation 24 hours is enough.

A)

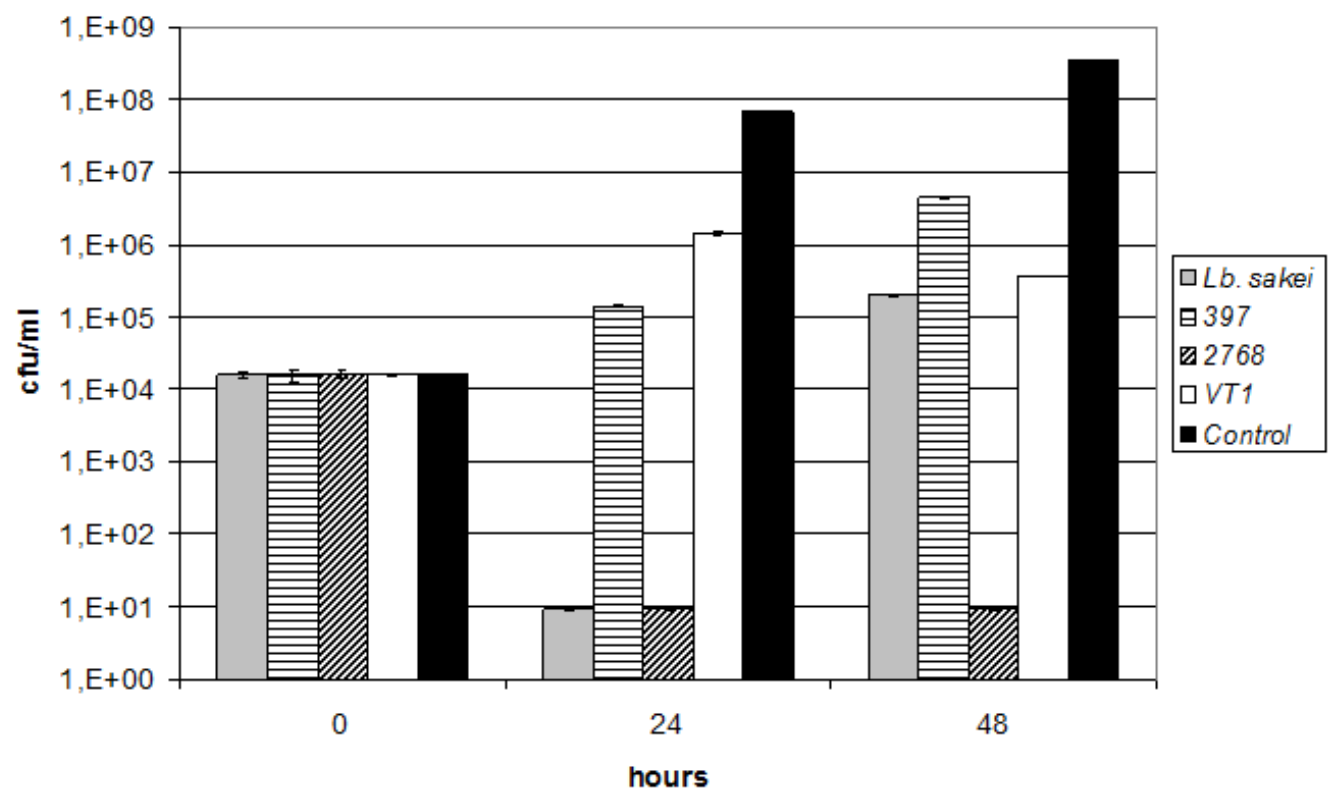

B)

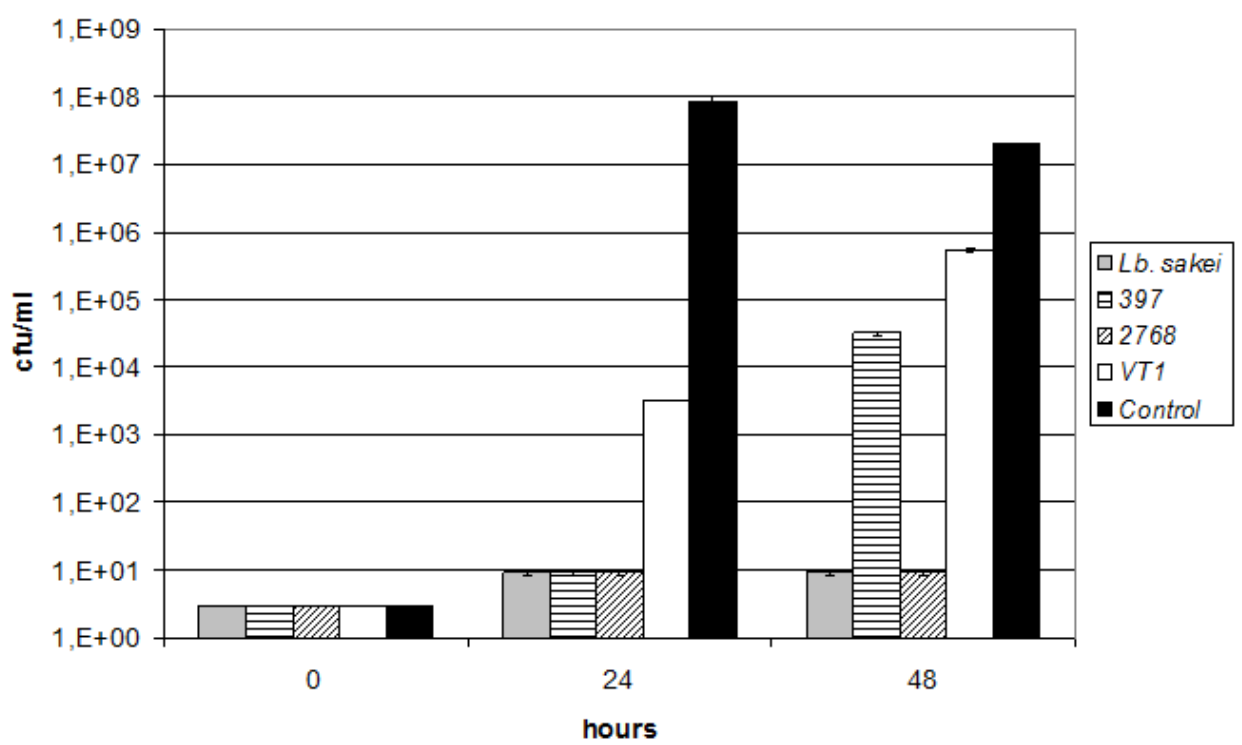

Fig. 2. Changes of the number of natural flora of the wheat (A) and oat (B) bran during the fermentation with and without starter culture3.4. Sourdough fermentation. 
The preparation of sourdough was carried out with the oat and wheat bran fermented by selected strains (Lb. delbrueckii subsp. bulgaricus 397, Lb. curvatus 2768). The sourdough fermentation was started with same amount $(1 \% \mathrm{w} / \mathrm{w}$ on flour basis) of investigated dry yeasts, respectively. The sourdough prepared without fermented bran, only with dry yeast, was used as control. The dough yield was in every case 160, which means the investigated sourdough was firm dough [29]. Since the Lactobacillus cell concentration in the fermented brans was enough high the initial cell number in sourdough was in range of $10^{8} \mathrm{cfu} / \mathrm{g}$ and due to this concentration the number of the Lactobacillus starter culture have reached the $10^{9} \mathrm{cfu} / \mathrm{g}$ to the end of fermentation in every case, which results agree with other reported LAB cell number in sourdough [10, 23, 24] (Table 4). No noticeable differences in Lactobacillus cell number were observed within the various samples, beside the different baker's yeast, which means that the yeasts have not influenced the growth of lactobacilli. In contrast with the fermented bran-enriched samples in the controls the living lactic acid bacteria population reached only $10^{5}-10^{8} \mathrm{cfu} / \mathrm{g}$. The activity of the starter culture in the fermented bran could be seen also from the $\mathrm{pH}$ of sourdough: in these samples it decreased significantly, the changes $(\Delta \mathrm{pH})$ were 0.7 to 1.25 in contrast with the control, where these changes were 0.29 to 0.8 , and naturally the $\mathrm{pH}$ values also were much less in the samples with fermented bran. The $\mathrm{pH}$ in the sourdoughs contain fermented bran was lower than others reported about spontaneously fermented sourdough [23, 24], however Meignen et al. [25] reported similar results with Lb. brevis starter culture. As from the microbial results can be seen also only beside the strain 2768 decreased the live cell number of yeast and among the yeasts only the Angel and Yestar, in spite of that this strain had only a weak or not any inhibition against these yeasts on the laboratory medium. In the other cases the yeast cell concentration to the end of the fermentation has not changed significantly, it was the same as the initial just as in the control sample. It has showed unambiguously that the fermented brans have not any inhibitory effect on the baker's yeast. However the maximal dough height showed great difference between the control and the bran-enriched samples. All of the sourdoughs prepared with fermented bran had less maximal height than the controls, which means that the fermented bran has some effect on yeasts after all and/or significantly influences the structure of the dough. This latter has been reported also by others, who explained it by the enhanced microbial enzymatic activity and the low $\mathrm{pH}$-mediated activation of cereal and bran endogenous (proteolytic) enzymes, which cause adversely effect on the rheological characteristics of dough by the degradation of structure proteins, among others gluten proteins [22]. However it can be stated that the fermented bran have not inhibitory effect on baker's yeast growth, their activity was partly influenced, which could be seen not only from the maximal dough height, but from the practical dough yield also. This latter in case of the sourdoughs contain fermented bran was greater than in the control, which could be explained by that the components of the flour were not transformed by the yeasts into volatile components, which cause losses in dough weight during the fermentation. To establish which factor influenced mainly the activity of the yeast and/or the structure of the dough the effect of $\mathrm{pH}$, the weak organic acids and the presence of Lactobacillus were investigated. Sourdoughs were prepared, but instead of fermented bran a native bran solution with adjusted $\mathrm{pH}$ (adjusted by $\mathrm{HCl}$, acetic acid and lactic acid, respectively, to the same value as it reached in the fermented bran) was added into the flour and baker's yeast mixture. Moreover Lactobacillus cells were added to the native bran and in an other samples fermented bran with adjusted $\mathrm{pH}$ to 6.9 were applied in the sourdough preparation. The results showed unequivocally the fermented bran and the acetic acid significantly influenced the maximal dough height negatively, while the addition of lactic acid did not influence the height significantly (Fig. 3.). It can be observed that the fermented bran with near neutral $\mathrm{pH}$ also had not effect on the dough height. From these results can be supposed that the acetic acid has great influence on the dough rising.

Table 4. Changes of the Lactobacillus and yeast cell number, the $p H$ and dough parameters during sourdough production. A) Control, B) Wheat bran, C) Oat bran.

A)

\begin{tabular}{|c|c|c|c|c|c|c|c|c|}
\hline \multicolumn{9}{|l|}{ Control } \\
\hline \multirow{2}{*}{ Starter culture } & \multicolumn{2}{|c|}{$\begin{array}{l}\text { LAB living cell } \\
\text { concentration (cfu/g) }\end{array}$} & \multicolumn{2}{|c|}{$\begin{array}{l}\text { Yeast } \\
\text { living cell concentration (cfu/g) }\end{array}$} & \multicolumn{2}{|l|}{ pH } & \multirow{2}{*}{$\begin{array}{l}\text { Practical dough } \\
\text { yield (\%) }\end{array}$} & \multirow{2}{*}{$\begin{array}{l}\text { Maximal dough } \\
\text { height }(\mathrm{mm})\end{array}$} \\
\hline & 0. hour & 16. hour & 0. hour & 16. hour & 0. hour & 16. hour & & \\
\hline Angel & $<10^{3}$ & $3.18 * 10^{5}$ & $4.15^{*} 10^{5}$ & $7.33 * 10^{5}$ & 5.80 & 4.99 & 97.37 & 41 \\
\hline Budafoki & $<10^{3}$ & $2.75 * 10^{5}$ & $1.3^{*} 10^{5}$ & $3.1 * 10^{5}$ & 5.79 & 5.5 & 96.95 & 41 \\
\hline Dr.Oetker & $<10^{3}$ & $2.25 * 10^{8}$ & $1.12 * 10^{8}$ & $2.46^{*} 10^{8}$ & 5.77 & 5.18 & 96.73 & 32 \\
\hline Yestar & $<10^{3}$ & $1.72 * 10^{7}$ & $9.4 * 10^{6}$ & $1.67 * 10^{7}$ & 5.78 & 5.36 & 97.77 & 30 \\
\hline
\end{tabular}


B)

\begin{tabular}{|c|c|c|c|c|c|c|c|c|}
\hline \multicolumn{9}{|l|}{ Wheat bran } \\
\hline \multirow[t]{2}{*}{ Starter culture } & \multicolumn{2}{|c|}{$\begin{array}{l}\text { Lactobacillus living cell } \\
\text { concentration (cfu/g) }\end{array}$} & \multicolumn{2}{|c|}{$\begin{array}{l}\text { Yeast } \\
\text { living cell concentration (cfu/g) }\end{array}$} & \multicolumn{2}{|l|}{$\mathbf{p H}$} & \multirow{2}{*}{$\begin{array}{l}\text { Practical dough } \\
\text { yield (\%) }\end{array}$} & \multirow{2}{*}{$\begin{array}{l}\text { Maximal dough } \\
\text { height (mm) }\end{array}$} \\
\hline & 0. hour & 16. hour & 0. hour & 16. hour & 0. hour & 16. hour & & \\
\hline Angel + 2768 & $4.49 * 10^{8}$ & $2.55 * 10^{9}$ & $4.15 * 10^{5}$ & $2.73 * 10^{4}$ & 4.93 & 3.71 & 99.01 & 16 \\
\hline Budafoki +2768 & $4.64 * 10^{8}$ & $2.68 * 10^{9}$ & $1.3 * 10^{5}$ & $1.0^{*} 10^{5}$ & 4.91 & 3.72 & 97.50 & 19 \\
\hline Dr.Oetker +2768 & $4.46 * 10^{8}$ & $2.63 * 10^{9}$ & $1.12 * 10^{8}$ & $1.32 * 10^{8}$ & 4.89 & 3.85 & 97.47 & 18 \\
\hline Yestar +2768 & $4.51 * 10^{8}$ & $2.68 * 10^{9}$ & $9.4 * 10^{6}$ & $3.64 * 10^{5}$ & 4.95 & 3.8 & 98.8 & 16 \\
\hline Angel + 397 & $9.78 * 10^{8}$ & $2.55 * 10^{9}$ & $4.15 * 10^{5}$ & $2.64 * 10^{5}$ & 4.73 & 3.75 & 97.96 & 23 \\
\hline Budafoki + 397 & $9.76 * 10^{8}$ & $2.24 * 10^{9}$ & $1.3 * 10^{5}$ & $1.6 * 10^{5}$ & 4.74 & 3.92 & 96.82 & 20 \\
\hline Dr.Oetker + 397 & $9.97 * 10^{8}$ & $2.85 * 10^{9}$ & $1.12 * 10^{8}$ & $1.21 * 10^{8}$ & 4.70 & 4.03 & 96.95 & 19 \\
\hline Yestar +397 & $9.73 * 10^{8}$ & $3.75 * 10^{9}$ & $9.4 * 10^{6}$ & $1.13 * 10^{6}$ & 4.78 & 3.83 & 98.95 & 23 \\
\hline
\end{tabular}

C)

\begin{tabular}{|c|c|c|c|c|c|c|c|c|}
\hline \multicolumn{9}{|l|}{ Oat bran } \\
\hline \multirow[t]{2}{*}{ Starter culture } & \multicolumn{2}{|c|}{$\begin{array}{l}\text { Lactobacillus living cell } \\
\text { concentration (cfu/g) }\end{array}$} & \multicolumn{2}{|c|}{$\begin{array}{l}\text { Yeast } \\
\text { living cell concentration (cfu/g) }\end{array}$} & \multicolumn{2}{|l|}{ pH } & \multirow{2}{*}{$\begin{array}{l}\text { Practical dough } \\
\text { yield (\%) }\end{array}$} & \multirow{2}{*}{$\begin{array}{l}\text { Maximal dough } \\
\text { height ( } \mathrm{mm})\end{array}$} \\
\hline & 0. hour & 16. hour & 0. hour & 16. hour & 0. hour & 16. hour & & \\
\hline Angel +2768 & $4.58 * 10^{8}$ & $1.85 * 10^{9}$ & $4.15 * 10^{5}$ & $4.45 * 10^{4}$ & 4.84 & 3.64 & 97.85 & 14 \\
\hline Budafoki + 2768 & $4.77 * 10^{8}$ & $2.08 * 10^{9}$ & $1.3 * 10^{5}$ & $2.8 * 10^{5}$ & 4.85 & 3.79 & 96.57 & 15 \\
\hline Dr.Oetker +2768 & $4.75 * 10^{8}$ & $3.23 * 10^{9}$ & $1.12 * 10^{8}$ & $2.85 * 10^{8}$ & 4.87 & 3.69 & 96.92 & 19 \\
\hline Yestar +2768 & $4.49 * 10^{8}$ & $1.99 * 10^{9}$ & $9.4 * 10^{6}$ & $6.9 * 10^{5}$ & 4.84 & 3.48 & 98.91 & 22 \\
\hline Angel +397 & $6.52 * 10^{8}$ & $2.12 * 10^{9}$ & $4.15 * 10^{5}$ & $1.5^{*} 10^{5}$ & 4.72 & 3.69 & 97.64 & 14 \\
\hline Budafoki +397 & $6.9 * 10^{8}$ & $3.65 * 10^{9}$ & $1.3 * 10^{5}$ & $1.8^{*} 10^{5}$ & 4.75 & 3.67 & 98.77 & 10 \\
\hline Dr.Oetker +397 & $6.8 * 10^{8}$ & $2.1 * 10^{9}$ & $1.12 * 10^{8}$ & $1.76^{*} 10^{8}$ & 4.78 & 3.85 & 96.86 & 23 \\
\hline Yestar +397 & $6.52 * 10^{8}$ & $2.61 * 10^{9}$ & $9.4 * 10^{6}$ & $1.35 * 10^{6}$ & 4.70 & 3.56 & 98.84 & 17 \\
\hline
\end{tabular}

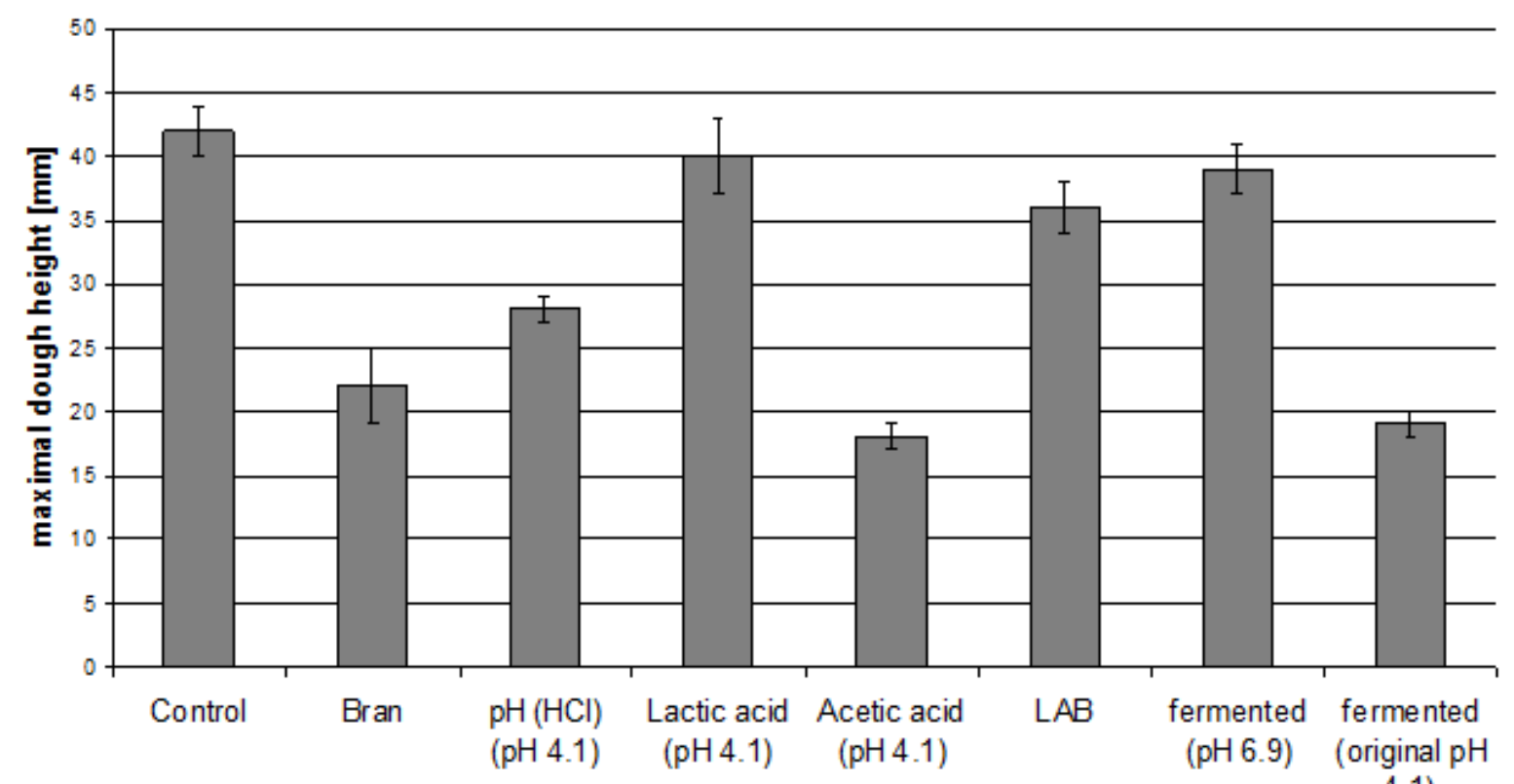

4.1)

Fig. 3. Effect of the pH, the organic acids, the bran and the living cells on the rising of dough (in case of oat bran and Lb. curvatus 2768; the applied yeast is Dr.Oetker).

\subsection{Bread Production}

Since the main function of sourdough is the bread production, the developed, fermented bran-enriched sourdoughs were used to produce bread. In this investigation the yeast Dr. Oetker and the Lb. curvatus 2768 strain were used. To compare the effects of different components the dough before the leavening was supplemented with bran; bran and lactobacilli; and fermented bran-enriched sourdough, respectively. The volume of the bread with bran was the lowest, that was to be expected, since it is well-known that the bran decreases the bread volume and weakens the structure and baking quality of the dough $[2,21]$. The structure and the volume of bread made with sourdough were similar or better than the control, due to the beneficial effect of the sourdough $[15,10,11]$ (Fig. 4.). The activity of the Lactobacillus in the sourdough bread is well demonstrated by the $\mathrm{pH}$ of the breads, since the $\mathrm{pH}$ of fermented bran-enriched sourdough bread was 
4.69 , while the $\mathrm{pH}$ value of the control, the bran supplemented and the lactobacilli and bran contained bread was $6.06,6,15$ and 5.58, respectively. To investigate the antimould efficiency of sourdough storage assay was performed and monitored the shelf life of the bread: a slice of bread from every samples was packed separately into a plastic bag and heat sealed and the presence or absence of spoilage mould was checked visually every day. The spoilage moulds appeared on the control samples already after 4 days, while on the bread with bran after 6 days and on the bread with added bran and lactic acid bacteria only after 7 days. In contrast to this on the bread which was prepared with fermented bran-enriched sourdough the spoilage molds have appeared only at the 10. day of storage, which confirm that the sourdough baking bread has a prolonged shelf-life.

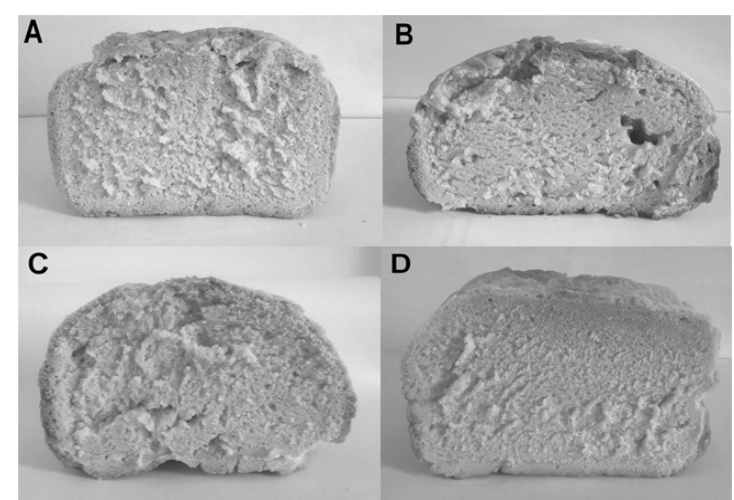

A: control, B: with bran, C: bran and Lactobacillus (Lb. curvatus 2768), D: with fermented bran-enriched sourdough

Fig. 4. Effect of the different components and sourdough on bread.

\subsection{Protein Profile of Breads}

Two-dimensional electrophoresis was used to find differences in the protein pattern of the bread samples made with different supplements (Table 1.). It has been widely reported in the literature that the proteolysis in sourdoughs is higher than in yeasted and unstarted doughs, however this activity is still unclear, because on the one hand the acidification of dough and on the other hand the enzyme activity also play a role in the proteolysis. Moreover the enzyme activity is divided between the various endogenous microbial and wheat flour-proteolytic enzymes, however the proteolysis in sourdoughs and the rheological consequences of gluten degradation are mainly based on the $\mathrm{pH}$-mediated activation of cereal enzymes, and the microbial enzymes play only a minor role $[22,23]$. The separation in $2-\mathrm{DE}$ was carried out on immobilized $\mathrm{pH}$ gradient containing strips between $\mathrm{pH}$ 3 and 10 and SDS-PAGE using molecular weight markers. Differences were found in the molecular weight region of 19 $\mathrm{kDa}$, which is the range of albumin and globulin polypeptides [24]. Spot SSP 101, 102 and 103 were detected in all samples with different intensity (Fig.5).

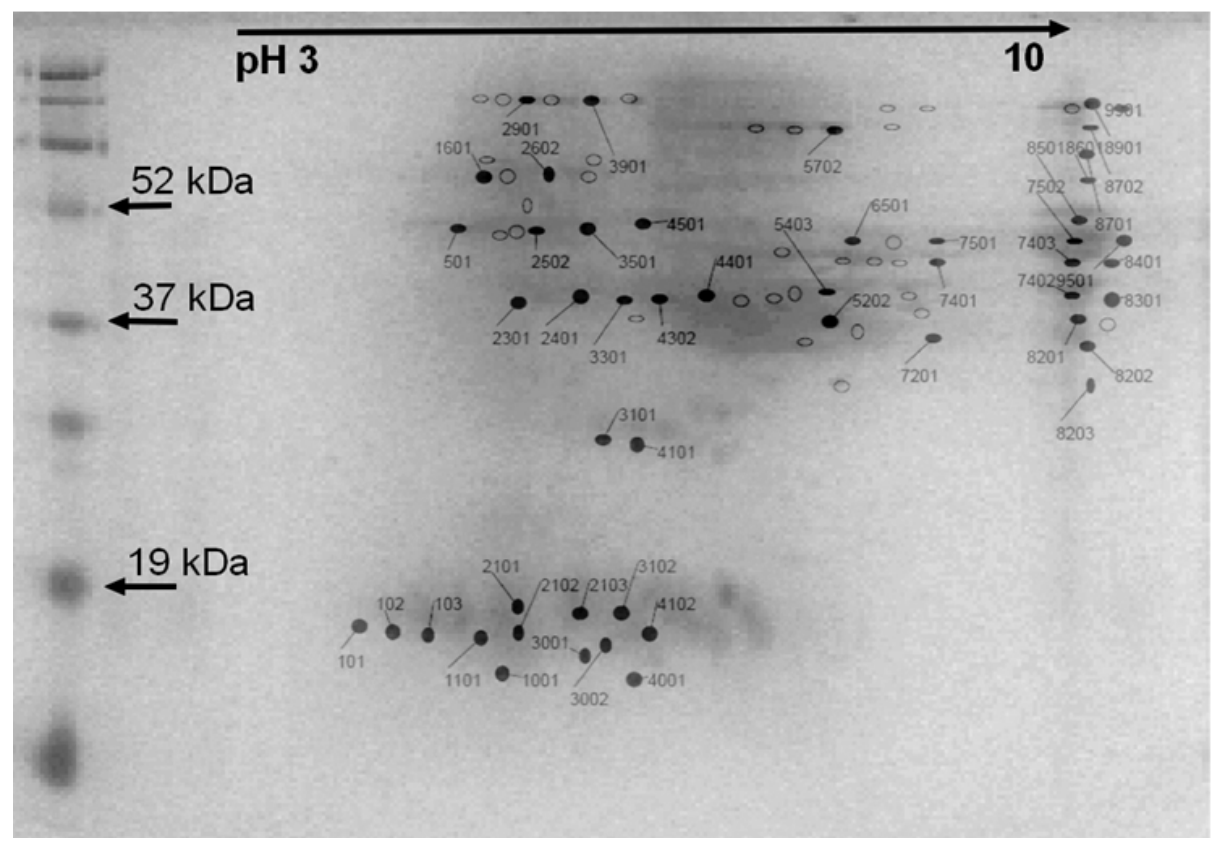

Fig. 5. 2D electrophoresis analysis of protein fractions in bread made with bran-enriched sourdough. 
The more intense spots were found in sourdough bread. In this region, spots SSP 2101, 2102 and 2103 were found in the bread supplemented with bran and Lactobacillus and sourdough bread, while the spots SSP 3002, 3101, 3102, 4001 and 4102 were detected in the sourdough bread only. Ten protein spots were found which were detected in the LAB containing bread samples only (SSP 501, 2101, 2102, 2103, 3501, 3602, 5402, 5403, 6502, 7902). These spots were detected with different intensity. Spot SSP 501 in the 37-52 $\mathrm{kDa}$ molecular weight region was more intense in the sourdough bread, but the spot SSP 2101 and 2103 in the 19 $\mathrm{kDa}$ region were less intense in the sourdough bread than in the bread supplemeted with bran and Lactobacillus. Twenty spots were found, which were detected in the sourdough bread only (SSP 3001, 3002, 3102, 4001, 4102, 4301, 4302, 5401, 6403, 7201, 7901, 8202, 8203, 8204, 8301, 8401, 8601, 8701, $9501,9901)$. In the molecular weight $(32-36 \mathrm{kDa})$ and isoelectric point (pI 6-8) regions of wheat gliadin spots were detected in all samples. In comparison with the control bread, where the analysis has showed 124 separate protein spots, in case of the bread prepared with fermented bran-enriched sourdough were 184 separate spots (in case of the bran supplemented and lactobacilli and bran added bread were 100 and 110 spots, respectively). It is presumable, that these new proteins come not only from the degradation of polypeptides and the endogenous proteins of lactobacilli, but could be bioactive components also, since it is reported by others that during sourdough fermentation new bioactive metabolites could be produced from the precursors present in the raw materials, among others in bran, and in this way the fermentation may increase the levels of various bioactive compounds $[3,2,15]$.

\section{Conclusion}

Nowadays there is an increased consumer demand to healthier, additive-free products with long shelf-life and with high dietary fiber content. Since bran is the one of the most common natural components for increasing the level of insoluble dietary fiber in baking, it is a superior raw material for development of new dietary fiber-rich cereal foods. However the application of the bran is difficult due to its several adverse technological and sensory properties. The pre-fermentation of bran could be a successful technology for improved technological properties and to enhance the bioactive potential of bran. The application of the fermented bran as starter component for sourdough production could improve the biological value of the bakery product made with the fermented bran enriched sourdough. We conclude that the application of well-characterized starter culture for bran fermentation is greatly advisable. Selected strains, other than the traditional sourdough species, could be used for the bran fermentation and this bioprocessed bran could be applied for sourdough fermentation. The fermented bran has not any significant influence on the commercial baker's yeast and the prepared sourdough has positive effect on the properties of bread, among others on the protein profiles and the shelf-life of the sourdough bread. The fermented bran could be used as functional ingredients for sourdough production.

\section{Acknowledgements}

Authors would like to acknowledge Chinese-Hungarian Intergovernmental Scientific and Technological Cooperation (Hungary: TÉT_12_CN-1-2012-0017, National Research, Development and Innovation Office; China: Program No. $6-30,[2013] 83$ ) for the financial support granted to the authors to implement this scientific cooperation.

\section{References}

[1] J. Wanga, B. Sun, Y. Cao, C. Wang. In vitro fermentation of xylooligosaccharides from wheat bran insoluble dietary fiber by Bifidobacteria, Carbohydrate Polymers 2010, 82:419-423.

[2] R. Coda, K. Katina, C. G. Rizzello. Bran bioprocessing for enhanced functional properties. Current Opinion in Food Science 2015, 1:50-55.

[3] K. Poutanen, L. Flander, K. Katina. Sourdough and cereal fermentation in a nutritional perspective. Food Microbiology 2009, 26:693-699.

[4] K. Katina, R. Juvonen, A. Laitila, L. Flander, E. Nordlund, S. Kariluoto, V. Piironen, K. Poutanen. Fermented wheat bran as a functional ingredient in baking. Cereal Chem. 2012, 89(2):126-134.

[5] O. I. Savolainen, R. Coda, K. Suomi, K. Katina, R. Juvonen, K. Hanhineva, K. Poutanen. "The role of oxygen in the liquid fermentation of wheat bran" Food Chemistry 2014, 153:424-431.

[6] N. Rosa-Sibakov, K. Poutanen, V. Micard. How does wheat grain, bran and aleurone structure impact their nutritional and technological properties? Trends in Food Science \& Technology 2014, 1-17.

[7] H.-R. Park, H.-J. Ahn, S.-H. Kim, C.-H. Lee, M.-W. Byun, G.-W. Lee. Determination of the phytic acid levels in infant foods using different analytical methods Food Control 2006, 17:727-732.

[8] C. I. Febles, A. Arias, A. Hardisson, C. Rodríguez-Alvarez, A. Sierra. Phytic acid level in wheat flours Journal of Cereal Science 2002, 36:19-23.

[9] N. M. Anson, E. Selinheimo, R. Havenaar, A.-M. Aura, I. Mattila, P. Lehtinen, A. Bast, K. Poutanen, G. R. M. M. Haenen. Bioprocessing of wheat bran improves in vitro bioaccessibility and colonic metabolism of phenolic compounds. J. Agric. Food Chem. 2009, 57:6148-6155.

[10] D. Ercolini, E. Pontonio, F. De Filippis, F. Minervini, A. La Storia, M. Gobbetti, R. Di Cagno. Microbial ecology dynamics during rye and wheat sourdough preparation. Applied and Environmental Microbiology 2013, 79 (24):7827-7836.

[11] L. De Vuyst, M. Vancanneyt. Biodiversity and identification of sourdough lactic acid bacteria. Food Microbiology 2007, 24:120-127. 
[12] L. De Vuyst, P. Neysens. The sourdough microflora: biodiversity and metabolic interactions. Trends in Food Science \& Technology 2005, 16: 43-56.

[13] K. Kulp and K. Lorenz (Eds.). Handbook of dough fermentations. 2003, Marcel Dekker, Inc. pp. 1-303. ISBN: $0-8247-4264-8$.

[14] R. S. Chavan, S. R. Chavan. Sourdough technology-A traditional way for wholesome foods: A review. Comprehensive Reviews in Food Science and Food Safety 2011, 10:170-183.

[15] S. Plessas, A. Fisher, K. Koureta, C. Psarianos, P. Nigam, A. A. Koutinas. Application of Kluyveromyces marxianus, Lactobacillus delbrueckii ssp. bulgaricus and L. helveticus for sourdough bread making. Food Chemistry 2008, 106:985-990.

[16] B. Bot, H. Sanchez, M. de la Torre, C. Osella. Mother dough in bread making. Journal of Food and Nutrition Sciences 2014, 2 (2):24-29.

[17] F. M. Anjum, I. Pasha, K. Ghafoor, M. I. Khan, M. A. Raza. Preparation of sourdough bread using a blend of bacterial culture and baker's yeast. Nutrition \& Food Science 2008, 38 (2):146 -153.

[18] I. Scheirlinck, R. Van der Meulen, A. Van Schoor, M. Vancanneyt, L. De Vuyst, P. Vandamme, G. Huys. Influence of geographical origin and flour type on diversity of lactic acid bacteria in traditional Belgian sourdoughs. Applied and Environmental Microbiology 2007, 73 (19):6262-6269.

[19] J. D. Legan. Mould spoilage of bread: The problem and some solutions. International Biodeterioration \& Biodegradation 1993, 32:33-53.

[20] D. K. Komlenić, V. Slačanac, M. Jukić. Influence of acidification on dough rheological properties. In: Rheology. J. De Vicente (Ed.), 2012, ISBN: 978-953-51-0187-1, InTech, Available from: http://www.intechopen.com/books/rheology/influence-of-acidi fication-on-dough rheological-properties
[21] M. Salmenkallio-Marttila, K. Katina, K. Autio. Effects of bran fermentation on quality and microstructure of high-fiber wheat bread. Cereal Chem. 78(4):429-435.

[22] C. Thiele, S. Grassl, M. Gänzle. Gluten hydrolysis and depolymerization during sourdough fermentation. J. Agric. Food Chem. 2004, 52:1307-1314.

[23] R. Di Cagno, M. De Angelis, P. Lavermicocca, M. De Vincenzi, C. Giovannini, M. Faccia, M. Gobbetti. Proteolysis by sourdough lactic acid bacteria: Effects on wheat flour protein fractions and gliadin peptides involved in human cereal intolerance. Applied and Environmental Microbiology, 2002, 68 (2):623-633.

[24] H. Robert, V. Gabriel, D. Lefebvre, P. Rabier, Y. Vayssier, C. Fontagné-Faucher. Study of the behaviour of Lactobacillus plantarum and Leuconostoc starters during a complete wheat sourdough breadmaking process. LWT 2006, 39:256-265.

[25] B. Meignen, B. Onno. Optimization of sourdough fermentation with Lactobacillus brevis and baker's yeast. Food Microbiology 2001, 18:239-245.

[26] D. J. Lane. 16S/23S rRNA sequencing. In: Stackebrandt E, Goodfellow M. (Eds.) Nucleic Acid Techniques in Bacterial Systematics. NewYork, Wiley. 1991, p. 115-149.

[27] M. R. A. Müller, M. A. Ehrmann, R. F. Vogel. Lactobacillus frumenti sp. nov., a new lactic acid bacterium isolated from rye-bran fermentations with a long fermentation period. International Journal of Systematic and Evolutionary Microbiology 2000, 50:2127-2133.

[28] K. Katina, A. Laitila, R. Juvonen, K.-H. Liukkonen, S. Kariluoto, V. Piironen, R. Landberg, P. Åman, K. Poutanen. Bran fermentation as a means to enhance technological properties and bioactivity of rye. Food Microbiology 2007, 24:175-186.

[29] P. Decock, S. Cappelle. Bread technology and sourdough technology. Trends in Food Science \& Technology 2005 16:113-120. 